\title{
Application of vibration monitoring to the detection of early misalignment and rub failures in a tidal turbine
}

\author{
Beatriz Fraga De Cal ${ }^{1}$
}

Received: 25 April 2018 / Accepted: 24 April 2019 / Published online: 8 May 2019

(C) Springer Nature Singapore Pte Ltd. 2019

\begin{abstract}
Research on tidal turbines has been mainly focused on the design for greater energy efficiency for the last ten years. However, achieving a reliable operation is becoming more and more crucial in current studies. This work presents a continuous monitoring of those turbines based on vibrations controls the control, this technique allows implementing predictive maintenance strategies. The vibration response is analysed in a laboratory test rig. That vibration can be produced by a phenomenon as frequent as a misalignment of the shaft as well as their consequences in the early production of partial rub of the rotor/stator. The response obtained shows that one can easily detect a vibration signal with a misalignment in the shaft of $50 \mu \mathrm{m}$. Also, the rub of the shaft/ seal is detected with the increase of the dynamic stiffness of the system from 12,87 to $14,30 \mathrm{KN} / \mathrm{m}$. Additionally, the resonance frequency also increases its value from 2400 to $2500 \mathrm{rpm}$. The application of this early detection on the watertight seal of a tidal turbine, would potentially avoid severe hazards in these equipment.
\end{abstract}

Keywords Tidal Turbine $\cdot$ Vibration response $\cdot$ Misalignment $\cdot$ Rubs $\cdot$ Dynamic stiffness

\section{Introduction}

Idea of the importance currently being taken by the research of tidal energy, as renewable energy sources, is the creation of the United Kingdom in the year 2015 [1] the ORJIP-OCEAN ENERGY, in which important state subsidies are provided, and where it performs projects and designs of tidal turbines to achieve a higher technical efficiency and efficient operation, that was created in 2003, with more than 30 million (£) of public funds, which were added companies such as Scottish Enterprise, which operates non-profit and is currently completely independent and self-financed.

In 2008, the EMEC, together with the company Open Hydro, installed as a research test the first tidal turbine $(0,3 \mathrm{MW})$ to generate electricity to the network in the UK, in addition to helping to better understand the behaviour of marine life around the machine and research on the potential effects at the population level of marine fauna, review and dissemination of environmental results.

Beatriz Fraga De Cal

p.fraga@udc.es

1 University of A Coruña, Spain, Inverness, UK
The research on the optimization in the production of electrical energy, by means of turbines of tidal current or marine, and its design, is at the moment at the center of its development and tests $[2,3]$.

It is important to point out other institutions such as the EMEC [4] that was created in 2003, with more than 30 million (£) of public funds, which were added companies such as Scottish Enterprise, which operates non-profit and is currently completely independent and self-financed. In 2008, the EMEC, together with the company Open Hydro, installed as a research test the first tidal turbine $(0,3 \mathrm{MW})$ to generate electricity to the network in the UK, Fig. 1.

The investigation of the efficiency and energetic performance of tidal turbines is being carried out in numerous organizations and research centers, which will be essential for their future and resulted; However, it will not be less important if we do not achieve equipment whose maintenance and operation reaches high technical safety $[5,6]$. Remember unsuccessful projects such as the Concorde plane, which was a high technological revolution, but which in 2003 made its last flight, among other reasons for the high maintenance cost. Airbus refused to take charge of its maintenance.

It is necessary, therefore, to apply a great deal of attention to provide the programming of the maintenance of tidal turbines [7] like can be an analysis system based on continuous 
Fig. 1 Tidal Turbine

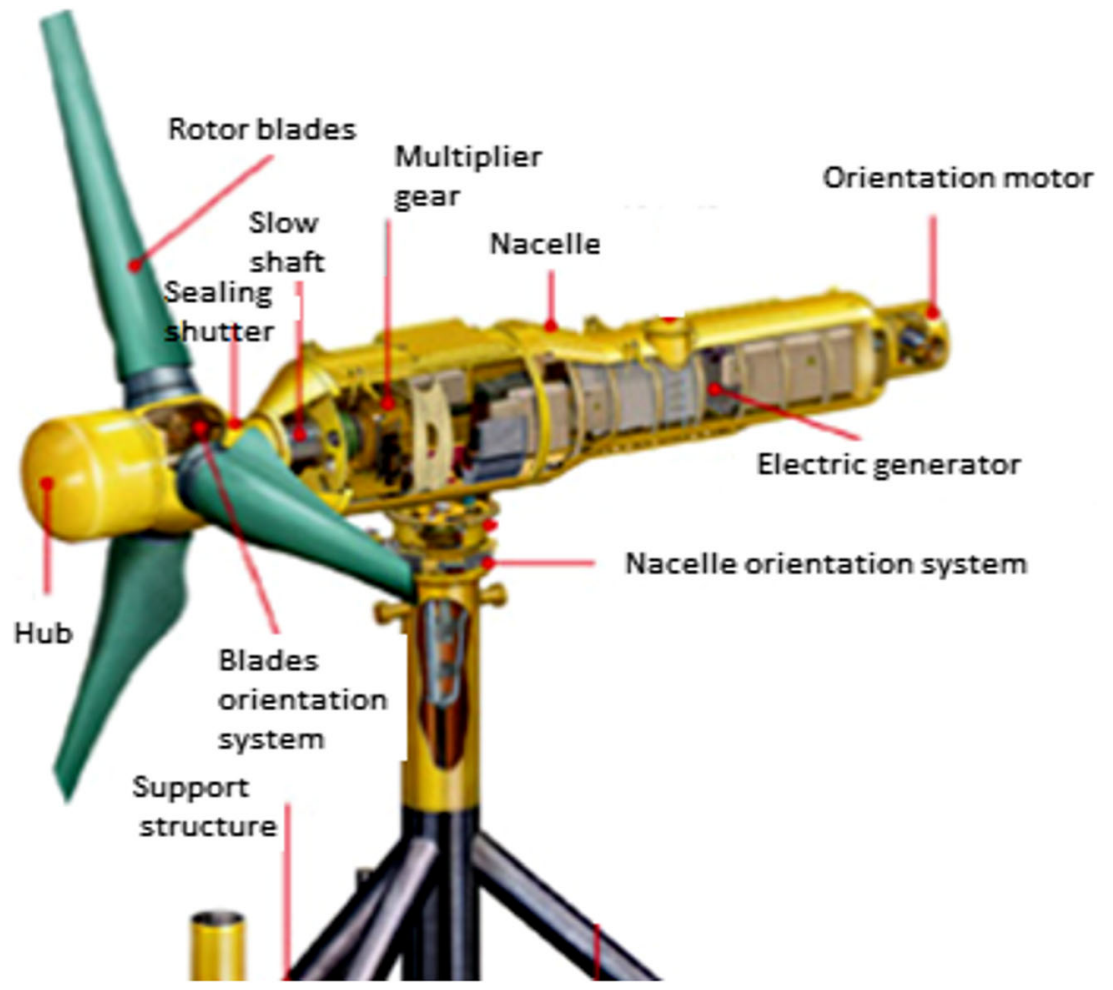

measurement of vibrations, which happen in the different systems most critical, and that keep direct relationship with the state of life of the components of the machine with which they are related, to predict a breakdown or inoperative before it happens, thus contributing to achieve a decision making as accurate possible, in addition to guaranteeing the service and contributing to the success of these renewable energy projects.

\section{Misalignment. Introduction}

The misalignment between supports of power transmission shafts and couplings is one of the most common latent defects of the machines and their installation. They may not be important at first, but they are underlying the montage, and over time can have devastating effects such as the rotor/stator rub, fatigue in the shaft, etc.

The corrections of misalignment in rotary systems have been studied by many experts over time in past due to the importance of this irregularity in the operation of the machines $[8,9]$. Nevertheless, there are very few studies on the early fault detection and prediction of a running system. Rubs, strong imbalances, permanent deformation, destruction of bearings, or cracks in the shafts [10] could be avoided by applying this strategy. Hence, the importance of including this monitoring study to recorded vibrations for to identify the misalignment.

Tidal turbines suffer the thrust of the marine currents, which do not keep the same direction neither a constant speed.
In fact, one of the conditions studied for their better operation and performance, is that the change of propellers' passage depending on the current speed of the current. In addition to the speed factor, propellers' orientation move towards the direction of marine currents in three dimensions [11]. Those changes in the angle of attack of the rotor towards the currents produce negative yields, besides creating strong vibrations and efforts in the turbine rotor. Although these controlled pitch helices have been installed, there will always be important vibrations [12].

The turbine of tests that was installed in the EMEC has been taken as a study model, and corresponds to the Fig. 2, its shaft of transmission being that of the Fig. 3.

A parallel misalignment between supports can be seen in Fig. 4, and includes:

- $\mathrm{F}_{1}$ and $\mathrm{F}_{2}$, the forces that come up in the misaligned support and cause the bending moment resulting from deflection due to misalignment.

- $\quad \mathrm{N}$ is the horizontal force consequence of the curvature of the shaft, which is transmitted to the bearings.

- $\quad \mathrm{P}$ is the resultant of the radial forces in each support.

Another fact that occurs due to misalignment is that the location of the center of the shaft in the bearings of both supports will appear in opposite quadrants, as Fig. 4 depicts for positions " 1 " and " 2 ", which is where the shaft will end up making the orbit of its movement. This condition does not 
Fig. 2 Tidal Turbine Model

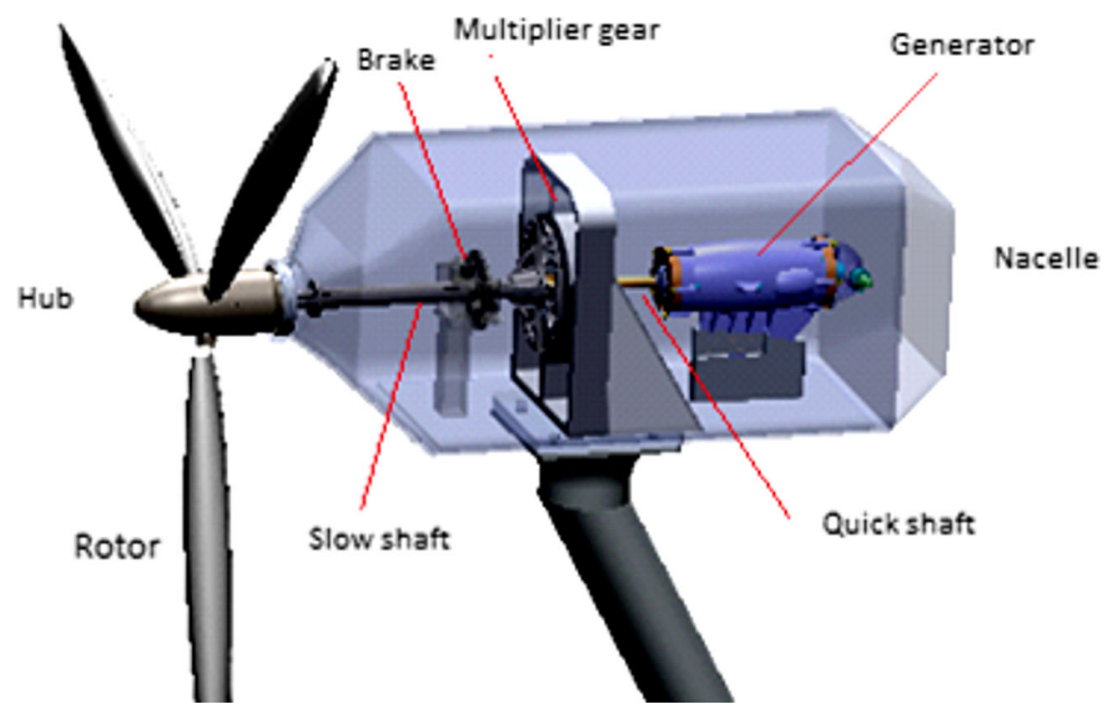

identify the misalignment anomaly by itself, but a simple control consisting of two $90^{\circ}$ induction transducers, it is very useful to avoid catastrophic failures [13].

A further consequence of the effects of shaft misalignment is the generation of radial loads in a specific direction. Those loads force the shaft move sideways. The radial load of misalignment has been assumed in the vertical plane. The movement of a shaft with this phenomenon is represented by [14]:

$$
\begin{gathered}
M \ddot{x}+D \dot{x}+K x=m r \Omega^{2} \cos (\Omega t+\delta) \\
M \ddot{y}+D \dot{y}+K y+K_{n} y^{2}=m r \Omega^{2} \sin (\Omega t+\delta)+P
\end{gathered}
$$

where: $x(t)$ and $y(t)$ are the deflections of the shaft in the horizontal and vertical direction, $\mathrm{t}$ is time; $\mathrm{M}, \mathrm{D}$ and $\mathrm{K}$ are respectively the mass, the damping and the stiffness of the considered rotor; $\mathrm{m}, \mathrm{r}$, and $\delta$ are the imbalance mass that always exists, the radius and the angular position of the same; $\mathrm{P}$ is the radial load of the misalignment, assumed in the vertical plane, $K_{n}$ is a coefficient of non-linear stiffness, which appears in the plane of misalignment, as a consequence of this displacement of the rotor in that plane " $y-y$ ".

The solution of the steady state of eqs. [1] is assumed as follows [15]:

$$
\begin{gathered}
x(t)=A_{x} \cos \left(\Omega t+a_{x}\right) \\
y(t)=A_{0}+A_{1} \operatorname{sen}\left(\Omega t+a_{1}\right)+A_{2} \operatorname{sen}\left(2 \Omega t+a_{2}\right)
\end{gathered}
$$

in which the $2 \mathrm{X}$ response is already observed, in the vertical plane of the misalignment: amplitude $A_{2}$, frequency $2 \Omega$ and phase angle $\alpha_{2}, A_{0}$ is the static displacement of the stopped rotor, as a consequence of the displacement of the shaft in that plane and that does not take place in another.

\section{Experimental set up}

In order to have a rotor control, the transducers shown in Fig. 5 will be installed. Two induction transducers at $90^{\circ}(\mathrm{H}$

Fig. 3 Slow roll and multiplier gear

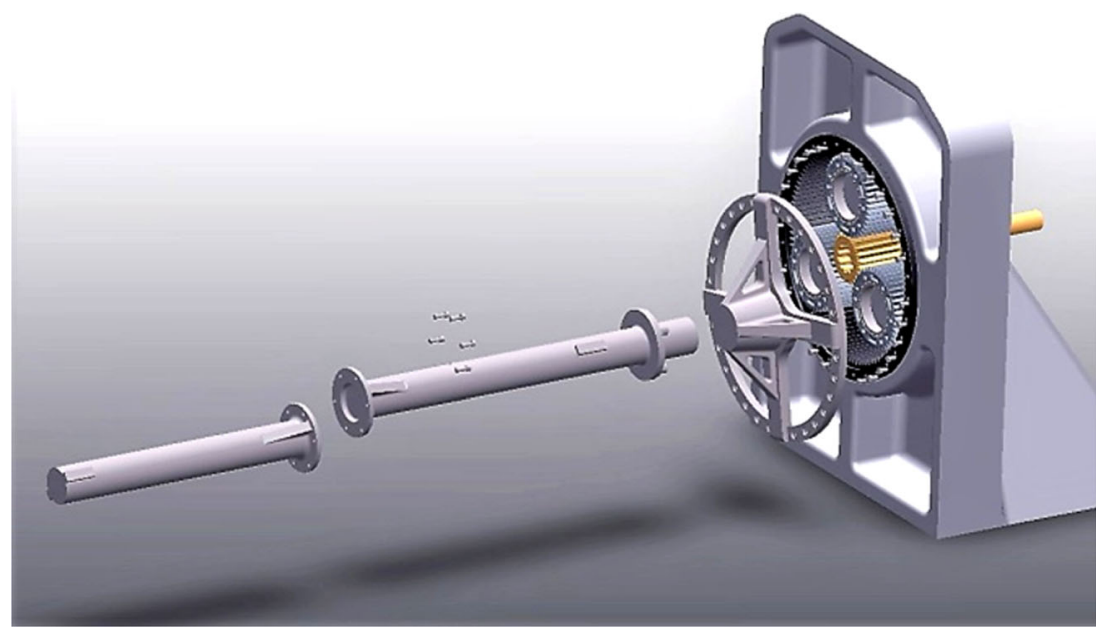


Fig. 4 Misalignment Scheme

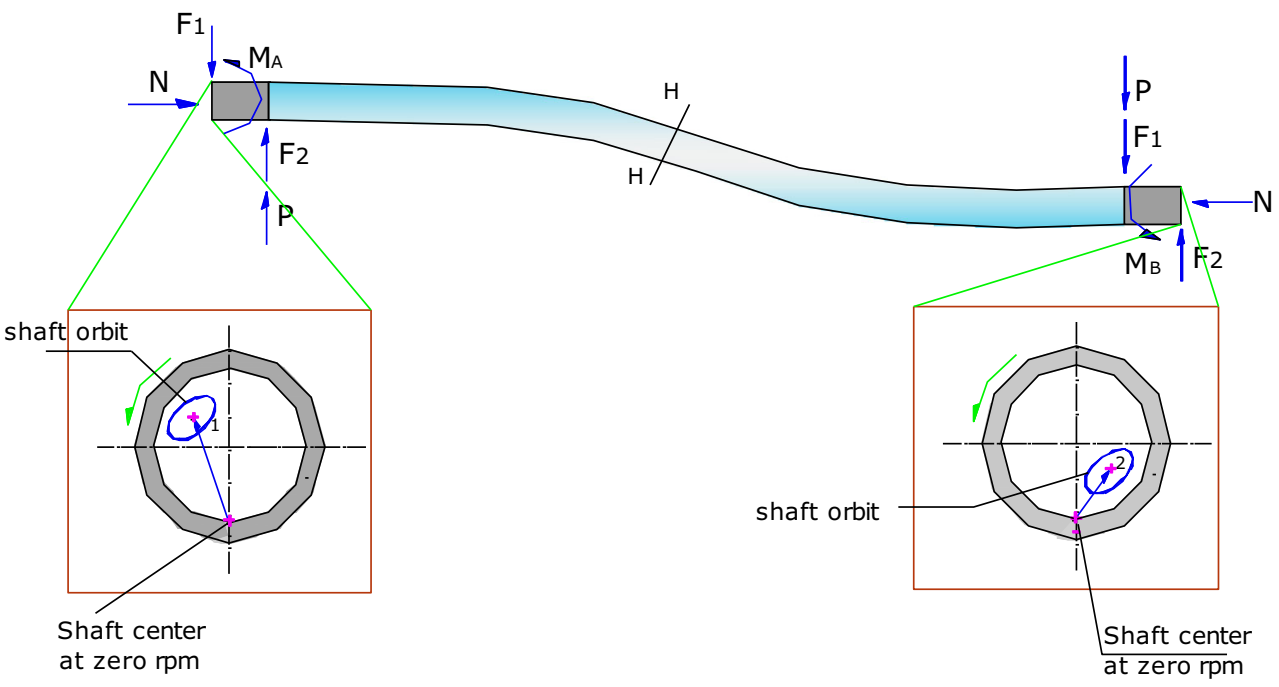

and V), plus another phase reference, marked " 1 " and " 2 ". An induction transducer " 3 " is placed in the center of the span to identify possible curvatures in the shaft, and even for possible modal analysis of the vibration of that first "slow shaft" of the turbine.

The dynamic rotation system that is analyzed can be based on to the rotor failure tests like in Fig. 6, which simulates the real models of tidal turbines. It consists of a mechanical base including an electric DC drive motor, a shaft-rotor with two test disks, bearings brackets, bearings, sealing seal, six magnetic induction transducers, three probe assemblies and a safety cover of polycarbonate.

The software used is the GE/Bently Nevada ADRE-208 Data Acquisition Interface and the 3500 Series Machinery Monitoring System.

The dimensions are $165 \times 340 \times 789 \mathrm{~mm}$, shaft diameter of $9,5 \mathrm{~mm}$ and maximum speed of $10,000 \mathrm{rpm}$. It also has a coupling device to the shaft, which constitute a mechanical seal or bearing in a pressurized fluid environment contained in a transparent polycarbonate shell along with its accessories: two induction transducers and another phase reference, plus a load frame to simulate eccentricities of the shaft in that housing.

Figure 7 outlines the model of rotor, where: $1 .-75 \mathrm{~W}$ drive motor, 2.- flexible coupling, 3.- antifriction/bronze bearings, 4.-1,63 kg disc -rotor, 5.-shaft centring support with four springs, 6.-aluminium disc for controlled imbalances, 7.-mechanical seal of $50 \mathrm{~mm}$ in length, radial clearance of $220 \mu \mathrm{m}$ and a circuit pressure of $10,342 \mathrm{~Pa}, 8$.- pressurized oil circuit in the gap of the seal, 9.- Horizontal and vertical induction transducers and phase reference transducer, 10.-induction transducers for axial vibration.

The rotor mass was placed about $6 \mathrm{~cm}$ from the bearing and this at $15 \mathrm{~cm}$ from the lubricated seal with liquid, with a distance between the bearings of $56,00 \mathrm{~cm}$. The rotor was driven by a 1/10 HP electric motor with a variable speed
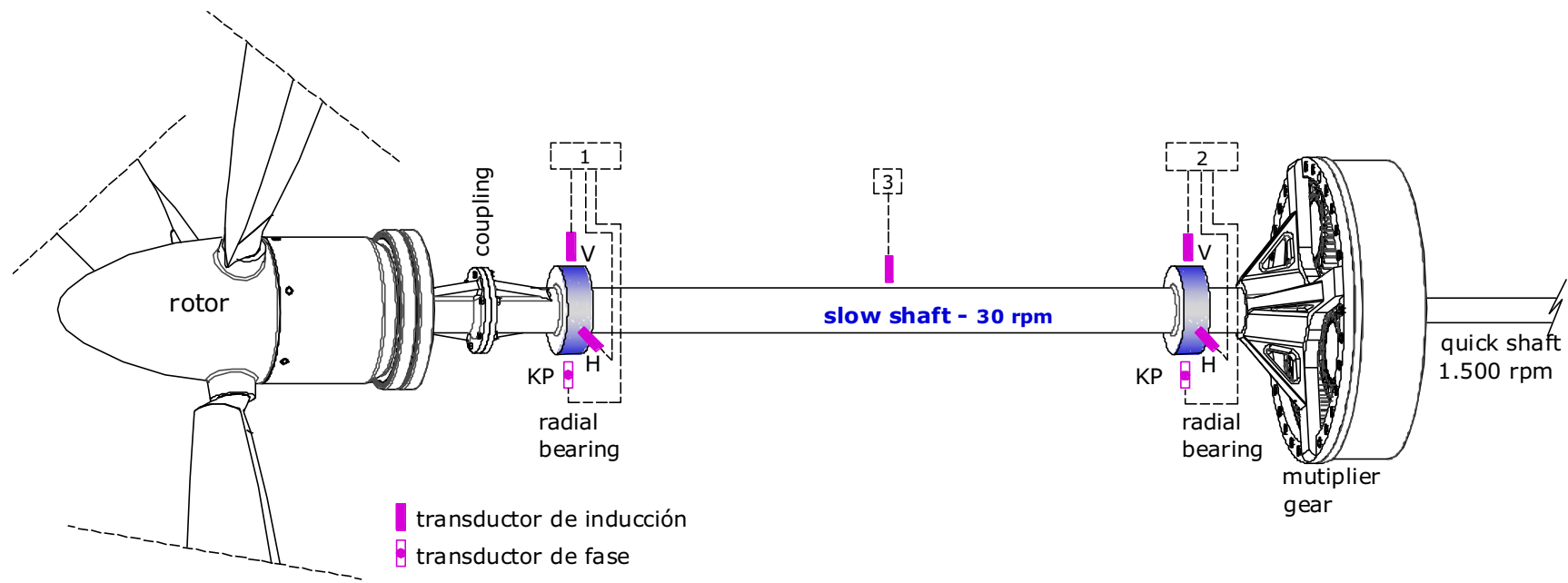

Fig. 5 Slow shaft. Installation of transducers 
Fig. 6 Experimental setup

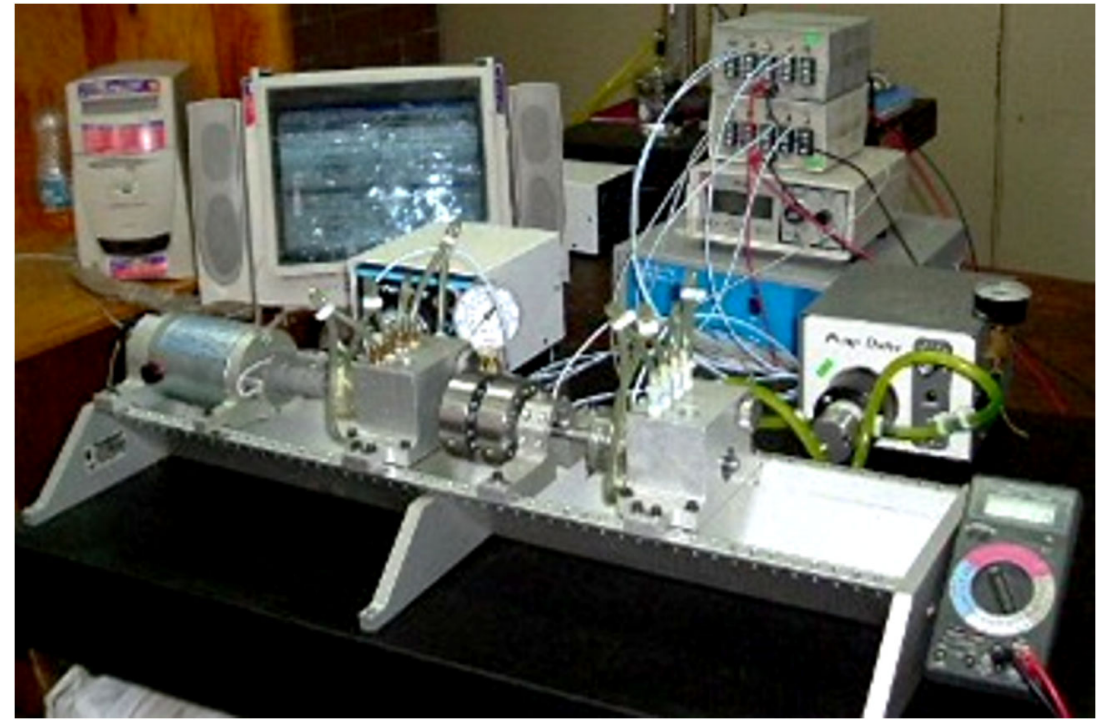

controller up to $10,000 \mathrm{rpm}$. A spring frame (5 in the figure shown) is installed to compensate for the gravity load on the rotor and center the shaft on the seal, which was provided with the oil film through four radial points at a pump outlet pressure of $14 \mathrm{kPa}$.

To cause a parallel misalignment, the bearing $3 \mathrm{~b}$ is provided with a vertical displacement of $50 \mu \mathrm{m}$ with respect to the $3 \mathrm{a}$ bearing. In this way, the misalignment load is exclusively vertical.

\section{Misalignment. Results}

The first test is performed, in principle, with the balanced rotor acceptable and without any other anomaly present, to obtain the fundamental parameters of the system, shown in Fig. 8 for the data collected in the seal immediate to bearing $3 \mathrm{~b}$ (transducer 9).

Diagram a) of this figure represents a diagram Nyquist [16]] of a rotor starting where one detects a first and only resonance at $2400 \mathrm{rpm}$, with amplitude of 6,6 mils and a residual value at $4000 \mathrm{rpm}$ of 1,55 mils. Diagram b) shows the evolution of the center of the shaft at that start, $0 \mathrm{rpm}$, located at the lowest point of the separating position of that shaft inside the seal, to the final operating position at $4000 \mathrm{rpm}$. The final position stabilizes in the first rightlower quadrant and at that point is where the rotor's vibration movement orbit occurs. Diagram b) indicates the shape of the orbit of this movement, which is almost circular, as it also, corresponds to an acceptable situation.

Then, in order to create the parallel misalignment, a vertical descending value of $50 \mu \mathrm{m}$ with respect to the bearing $3 \mathrm{a}$ is carried out in the support of the bearing $3 \mathrm{~b}$. Thus, the graphic results of Fig. 9 are obtained also for seal immediate to the bearing $3 \mathrm{~b}$, which shows the changes that appear in the position of the center of the shaft, from the start at $0 \mathrm{rpm}$ to its nominal operation (graph a), highlighting the new position of that center of shaft in the seal clearance, which takes place in the upper right quadrant, and which is identified with a situation of instability [17] and the disposition of an "angle of attack", higher to $90^{\circ}$. The orbit b) of that figure is transformed into a very "elliptical" profile, which is identified like an important radial force or restriction of movement in an almost vertical direction.

A further misalignment, made with the machining of the bearing seat $3 \mathrm{~b}$ at a value of $75 \mu \mathrm{m}$ will increase the radial

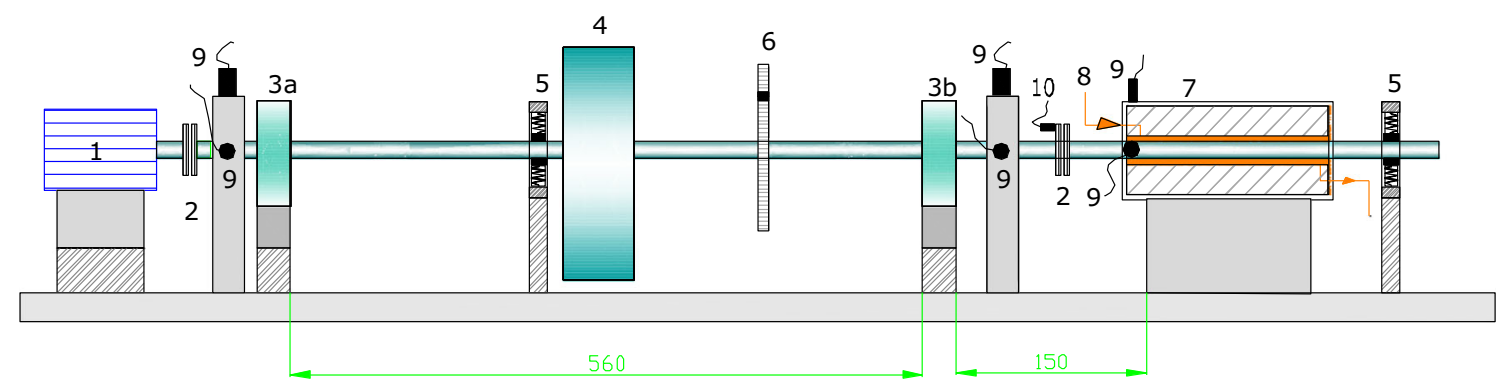

Fig. 7 Test rotor scheme 


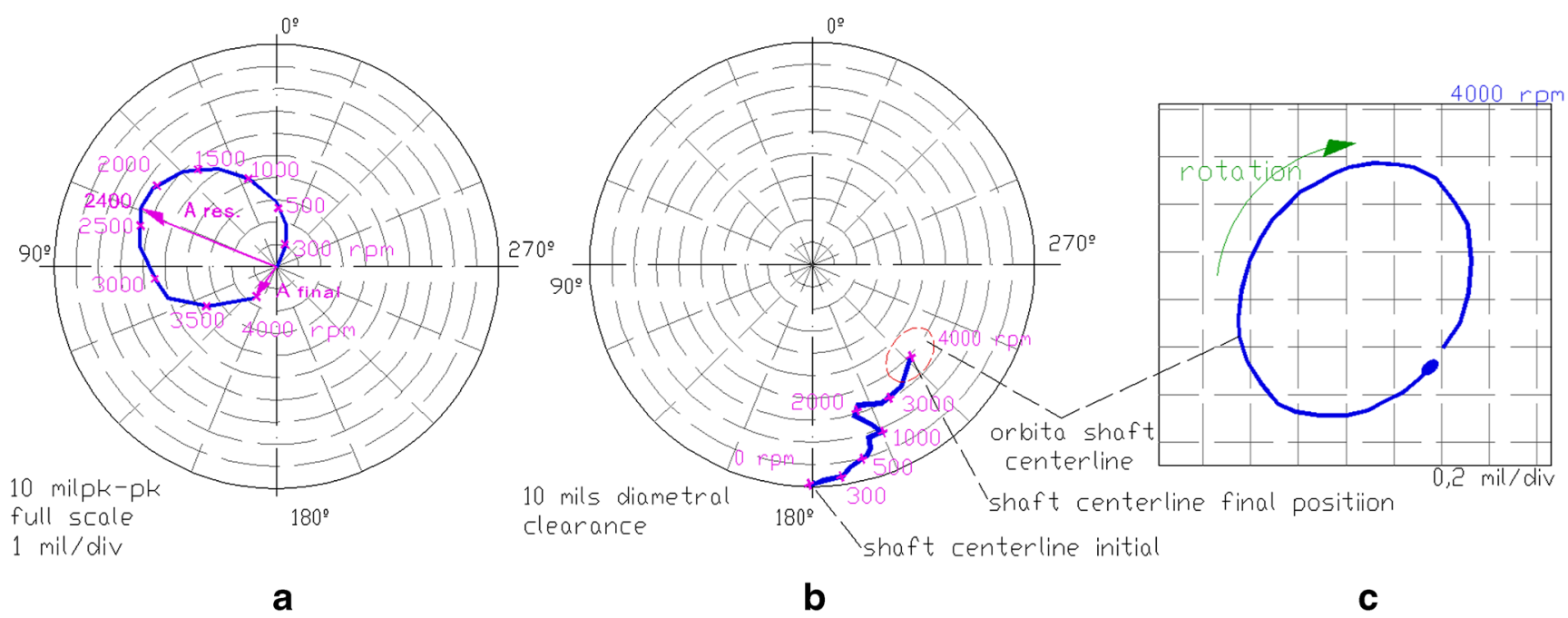

Fig. 8 Rotor behaviour in stable situation

force produced on the shaft and then obtain the graphs of Fig. 10. The position of the shaft center is now located even higher in that upper quadrant of the seal clearance, as consequence of that greater vertical radial load, and places it on the upper side surface of that seal. Simultaneously, the shape of the orbit becomes an "eight", meaning that the shaft even has a reverse rotation. A machine that has these characteristics must be inspected immediately.

As a result, the answer corresponds to the misalignment that occurs in the vertical plane. The responses of a cascading spectrum and another of amplitude/time in the vertical and horizontal transducers must be obtained. Figure 11 already shows the almost exclusive characteristics of the misalignment phenomenon, which are [8]:
- $\quad 1 \mathrm{X}$ and $2 \mathrm{X}$ response (response to the frequency equal to the operating speed and twice this, respectively), which are simultaneous in the resonance frequency.

- Increase in the amplitude of the 1X response throughout the operating range, as a result of the mass imbalance caused by the deflection of the shaft into the seal's clearance.

- "Elliptical" and "eight" shaped orbits due to the radial load associated with the misalignment.

- At a rotor speed equal to half the resonance frequency, there is already an increase in the amplitude of the $1 \mathrm{X}$ response as imbalance due to the mentioned deflection of the shaft caused by the strong radial load of the misalignment.

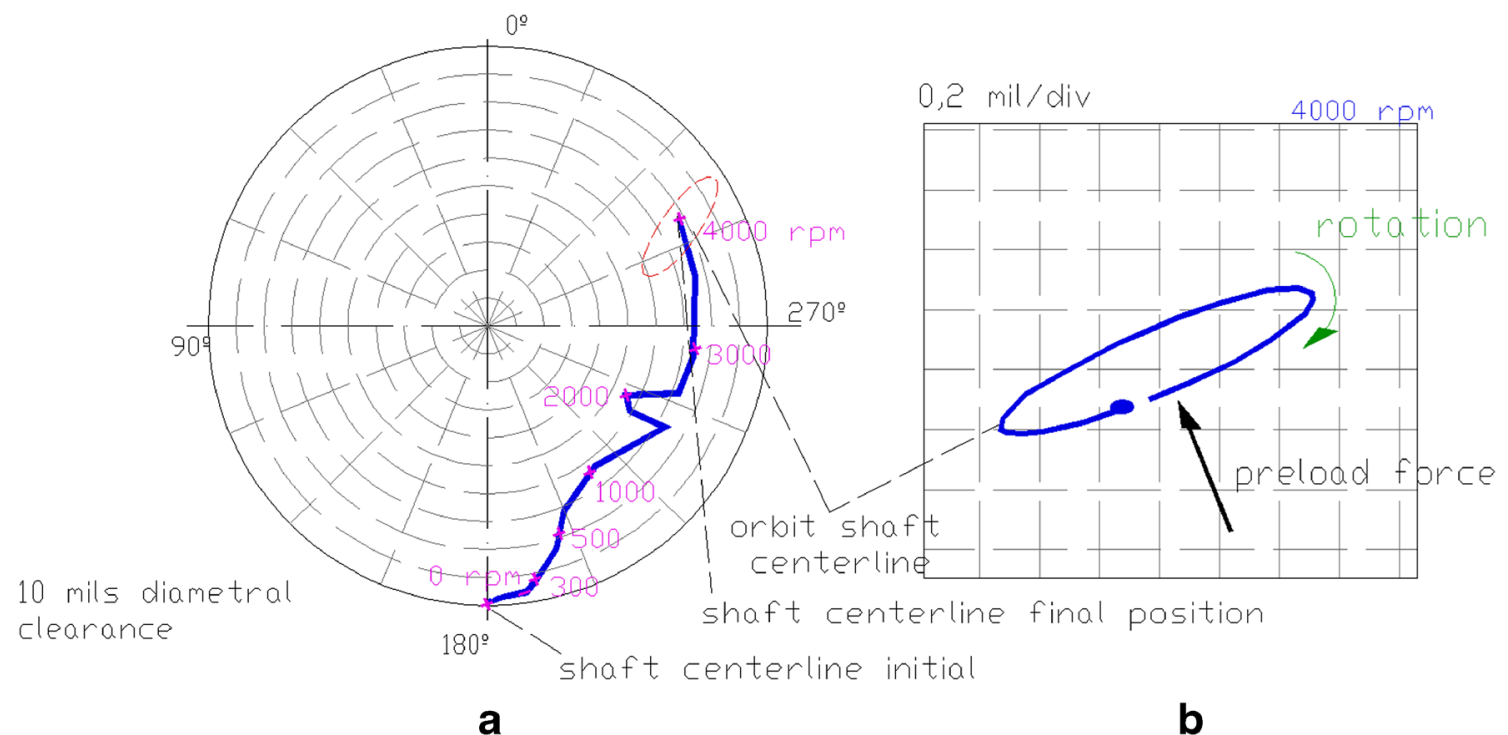

Fig. 9 State of misalignment in the initial phase 


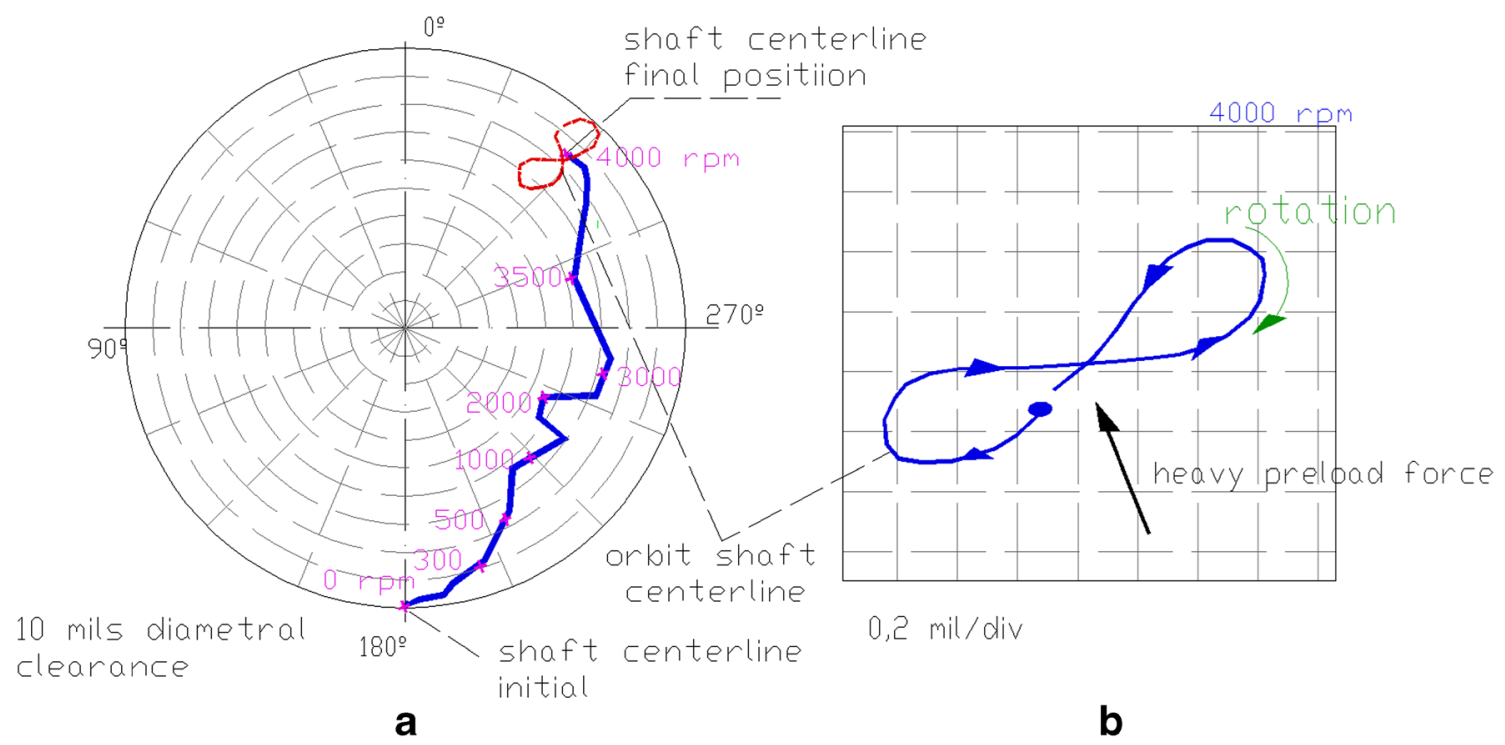

Fig. 10 Seal behaviour, with greater misalignment

Figure 12 depicts the separate time amplitude/response of both transducers on the $\mathrm{X}$ and $\mathrm{Y}$ axes. Graph a) refers to the response before the misalignment, in which one can see how the responses of the transducers are similar in both directions, vertical and horizontal, with the displacement of $90^{\circ}$ in the reference mark of phase and amplitude of 1,4 mils zero-pk.

Graph b) of this figure reveals the response to misalignment. In the vertical plane the previous sine wave is altered with several harmonics and increases its amplitude. However, in the horizontal plane have an almost sinusoidal shape and less amplitude. This is because in that plane there is no misalignment, but a modified form of a sinusoid due to the linkage of existing signals between both horizontal and vertical planes.

The different response, in the $\mathrm{X}$ and $\mathrm{Y}$ directions, is related to the phenomenon of misalignment.

It is widely known that a binding characteristic of the misalignment is the axial vibration, which is obtained from the transducers placed in the coupling and that generally has an approximate value to the half of the lateral response in addition to presenting a position of the shaft/center against the upper quadrants in lower for the bearings $3 a$ and 3b, according to Fig. 4.

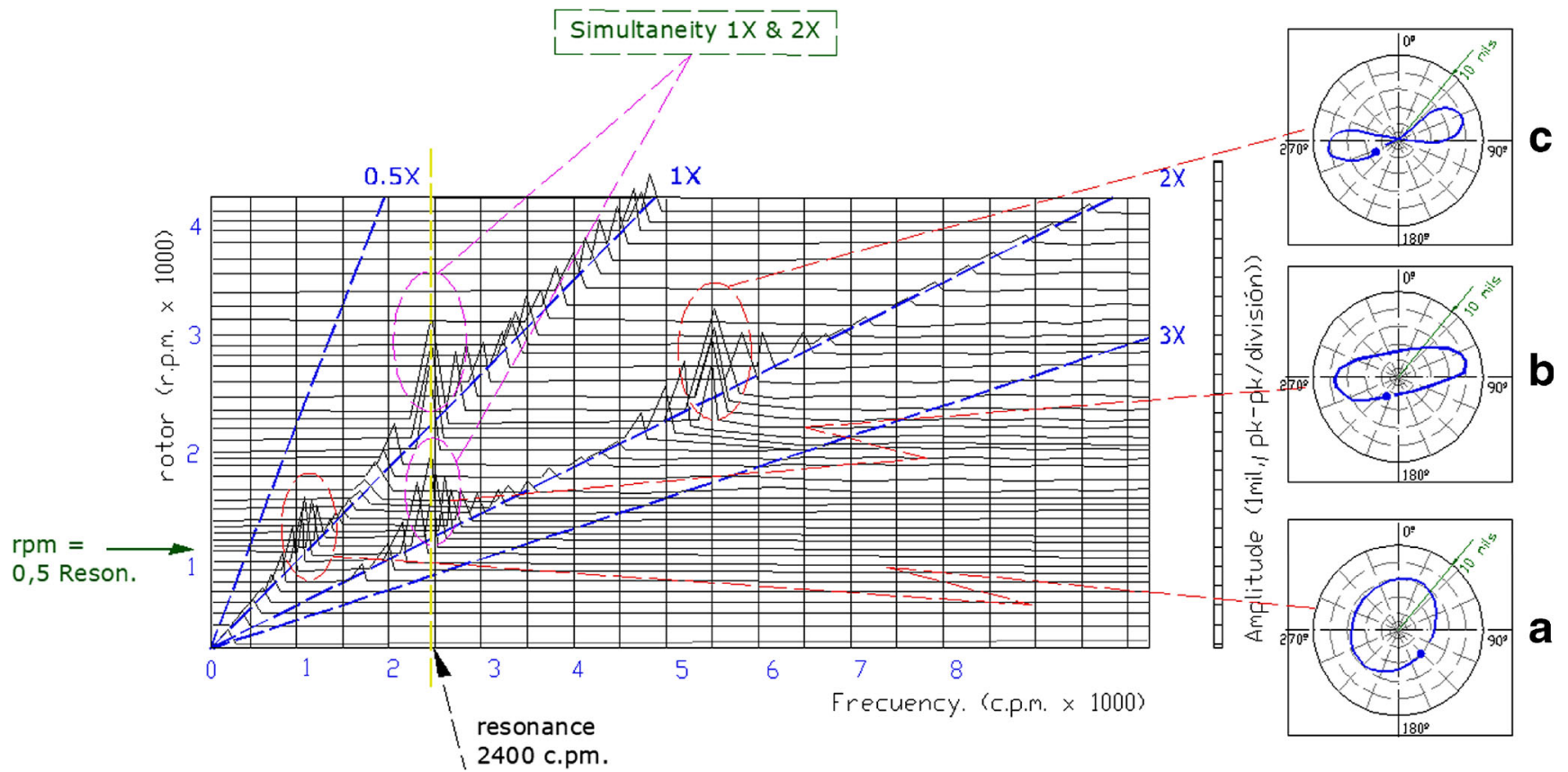

Fig. 11 Cascade Spectrum 

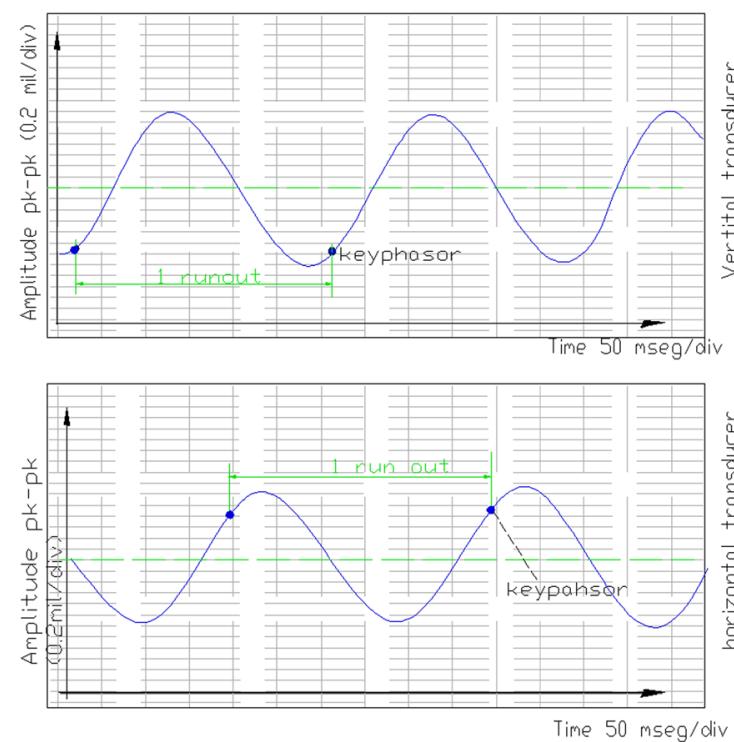

a

Fig. 12 Amplitude/time response in horizontal and vertical transducers

\section{Misalignment and rub. Results}

An immediate consequence of the misalignment is often the partial rubbing [18]. As this anomaly increases, the shaft contact with the static parts of bearings or seals will appear, as a side effect of that misalignment, and even transverse fissures may appear on the shaft [19]. To experience the effect of rubbing and not having to wait for it to happen, the shaft moves inside the seal until it reaches that friction through the springs " 5 " in Fig. 7, and thus observe its response.

With the misalignment only, there is no modification of the dynamic stiffness [20] but if it appears with the rubbing. The dynamic stiffness of a rotor is the attenuation that presents to a disturbance, so that:

$$
\begin{gathered}
\text { Vibration Response }=\frac{\left\{\begin{array}{c}
\text { Perturbation } \\
\text { Force }
\end{array}\right\}}{\left\{\begin{array}{c}
\text { Dynamic } \\
\text { Stiffness }
\end{array}\right\}}=\overrightarrow{\mathrm{R}}=\frac{\overrightarrow{\mathrm{F}}}{\overline{\mathrm{K}_{\mathrm{DS}}}} \\
\overrightarrow{K_{D S}}=\underbrace{K-M \Omega^{2}}_{\begin{array}{c}
K_{D}=\text { Direct } \\
\text { Dynamic Stiffness }
\end{array}}+\underbrace{j(\text { Dynatifnes }}_{\begin{array}{c}
K_{Q}=\text { Quadrature } \\
\text { Dynamic Stiffness }
\end{array}}
\end{gathered}
$$

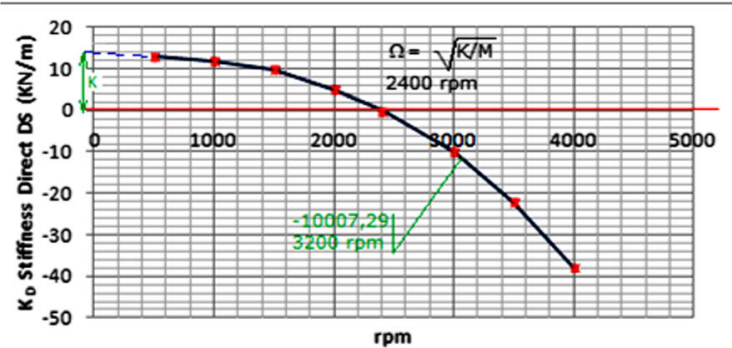

rpm
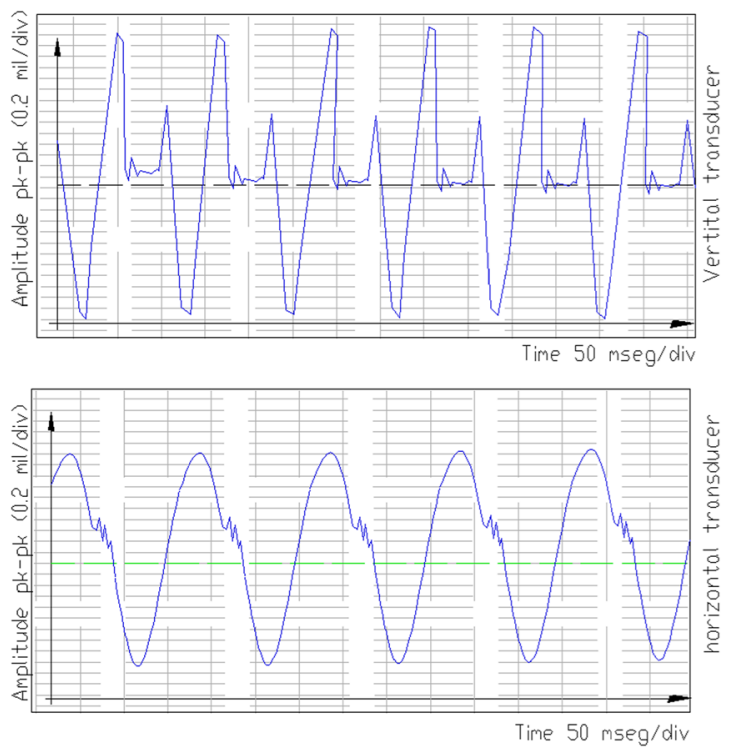

b

where: M: rotor mass, K: rotor stiffness, $\Omega$ : rotation speed, D: damping, $\omega$ : rotation of the perturbation force $(\omega=\Omega)$, in the disturbance by mass imbalance), $\lambda=$ average circumferential velocity of the fluid flow in the mechanical seal.

To carry out this verification, the calculation of the rigidity parameters is developed with a test of a given imbalance and without other phenomena added such as misalignment or rubbing caused, at $3200 \mathrm{rpm}$, to obtain the dynamic stiffness taking into account the zero-peak amplitude response [21]. The force produced by the unbalance of the given mass, which is $0,1 \mathrm{~g}$ in a radial position of $35 \mathrm{~mm}$ to $90^{\circ}$, using the disc described " 6 " in Fig. 7, at 3200 rpm, is:

$$
\begin{gathered}
\vec{F}=m_{u} \Omega^{2} e^{j \delta}= \\
\left(0,1 * 10^{-3} \mathrm{~kg}\right)\left(35^{*} 10^{-3} \mathrm{~m}\right) * \\
{\left[3200 \mathrm{rpm}(2 \pi \mathrm{rad} / 1 \mathrm{rev})\left({ }^{1 \mathrm{~min} / 60 \mathrm{seg}}\right)\right]^{2} \angle 90=394,12 * 10^{-3} N \angle 90^{\circ} \text { p.p. }}
\end{gathered}
$$

The vibration response that was obtained is: $\mathrm{A}=1,5$ mils $\angle 262^{\circ}=0,039^{*} 10^{-3} \mathrm{~m} \angle 262^{\circ}$.

Fig. 13 Dynamic Stiffness without rub

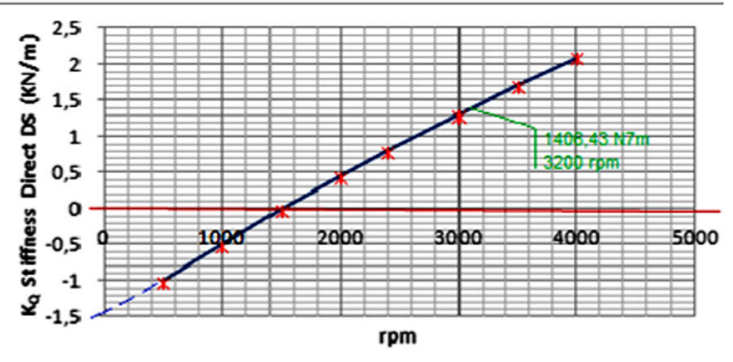




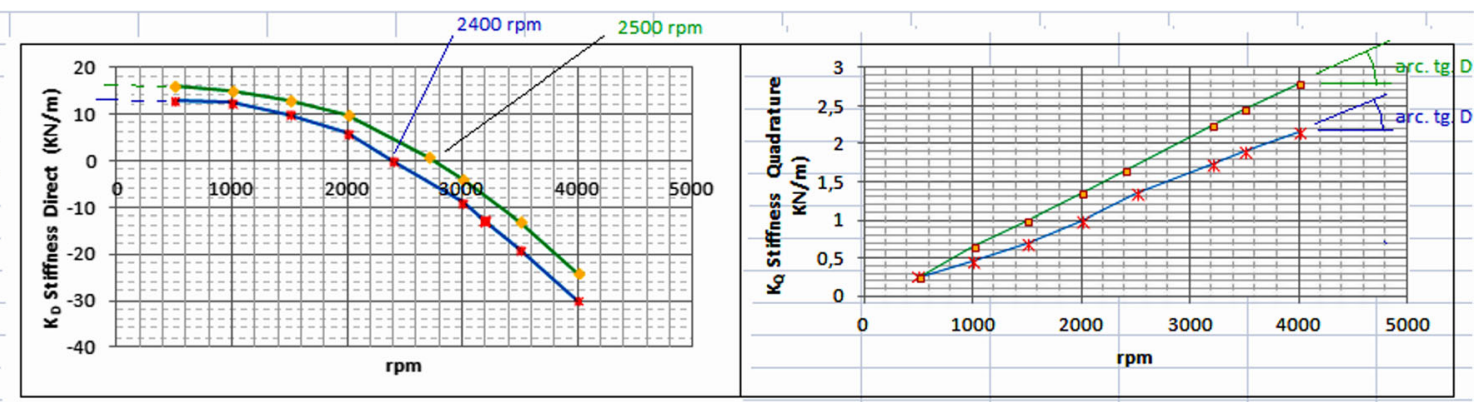

Fig. 14 Dynamic stiffness of the rotor model without rubbing and with rubbing, in the vertical plane of rub and misalignment

$$
\begin{gathered}
\text { Dynamic Stiffness }=\vec{K}_{D S}=\frac{\vec{F}}{\vec{R}}= \\
\frac{F e^{j \delta}}{A e^{j a}}=\frac{m r_{u} \Omega^{2}}{A} e^{j(\delta-\alpha)}=\frac{m r_{u} \Omega^{2}}{A} \angle(\delta-\alpha)^{\circ}= \\
K_{D S}=\frac{394,12 * 10^{-3}}{0,039 * 10^{-3}} \frac{N}{m} \angle(262-90)=10105,64^{N} / m^{\circ} \angle 172^{\circ}
\end{gathered}
$$

- Direct Dynamic Stiffness: $\mathrm{K}_{\mathrm{D}}=\mathrm{K}_{\mathrm{DS}}{ }^{*} \cos \theta=10,105,64 \mathrm{~N} /$ m) $* \cos 172^{\circ}=-10,007,29 \mathrm{~N} / \mathrm{m}$.

- Quadrature Dynamic Stiffness: $\mathrm{K}_{\mathrm{Q}}=\mathrm{K}_{\mathrm{DS}} * \sin \theta=$ $10,105,64(\mathrm{~N} / \mathrm{m}) * \sin 172^{\circ}=1406,43 \mathrm{~N} / \mathrm{m}$

This first test is performed with the same determined weight of imbalance $0,1 \mathrm{~g} \angle 90^{\circ}$, at different speeds, to obtain the components of the dynamic stiffness depending on the rotation speed, which are represented in Fig. 13.

The graphs of Fig. 13 are thus obtained. The values of calculation example for $3200 \mathrm{rpm}$ are marked, the value of the resonance is also indicated when in the real component $Z_{D}=0$, which is produced when $\Omega=\sqrt{ }(K / M)=2400 \mathrm{cpm}$. In that same figure, with the prolongation of the parabola of $Z_{\mathrm{D}}$, for $\omega=0$, we obtain $\mathrm{K} \approx 12,8 \mathrm{KN} / \mathrm{m}$.

The same test is now carried out, but with the rub already induced by the mentioned springs, with the same unbalance weight $0,1 \mathrm{~g} \angle 90^{\circ}$, at different speeds to obtain the components of the dynamic stiffness as a function of the speed of rotation.

The results are shown in Fig. 14 in which their graphs are compared: no rubbing (blue lines); and with the rubbing (green lines).

From above graphs of Fig. 14, the following characteristics are observed:

- The direct component $Z_{D}=0$, which occurs at the value $\Omega=\sqrt{ }(\mathrm{K} / \mathrm{M})=2400 \mathrm{rpm}$ in the situation without rub, now appears at $2500 \mathrm{rpm}$, as a consequence of the increase in modal "K" stiffness with the rub, which goes from 12,8 to $14,3 \mathrm{KN} / \mathrm{m}$, which is also obtained in the prolongation of the parabola of $\mathrm{K}_{\mathrm{Q}}=\mathrm{K}-\mathrm{M} \Omega^{2}$ when $\Omega=0$.

- The imaginary component $Z_{Q}=j D(\omega-\lambda \Omega)$, that in this case, as a result of being a disturbance caused by an imbalance of mass, as mentioned, this frequency of disturbance $\omega$ is equal to the speed of rotation $\Omega$, so $Z_{Q}=j D$ $(\Omega-\lambda \Omega)=\mathrm{j} D \Omega(1-\lambda)$, and besides being a solid bronze bearing $\lambda=0$, therefore: $\mathrm{Z}_{\mathrm{Q}}=\mathrm{D} \Omega, \mathrm{Z}_{\mathrm{Q}}=0$ for zero speed.

In this graph, the damping is determined by the slope of the straight line, which is made greater in the case of rubbing, from 4,19 to $5,20 \mathrm{~N} . \mathrm{s} / \mathrm{m}$.

In the horizontal plane, the graphs obtained with the rubbing caused in the vertical plane have almost no modification
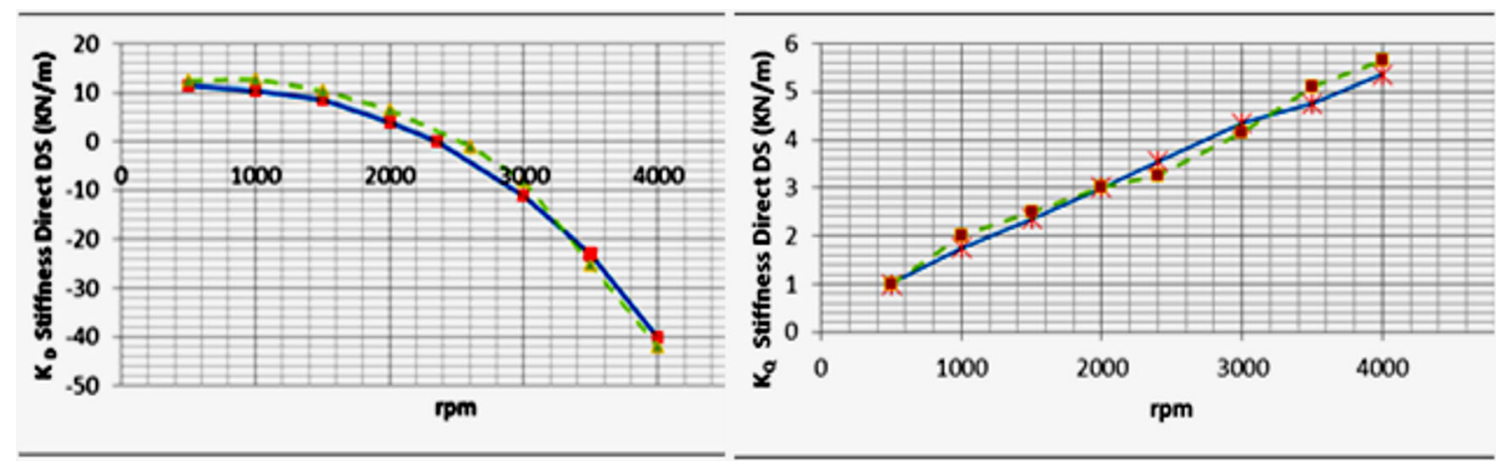

Fig. 15 Components of the dynamic stiffness in the horizontal plane, with rub and misalignment, and without rub 
in the rigidity, because in this plane there is no restriction. Its small difference is due to couplings and inertia of the phenomenon that of misalignment that was forced in the vertical plane, according to Fig. 14, in which the trace of blue colour corresponds to the non-rubbing situation, and that of green colour, to rubbing and misalignment in the horizontal plane.

Figure 14 and Fig. 15 describe the signal difference and the different stiffness in the plane that contains the misalignment and the one that doesn't.

\section{Conclusions}

(1) It is shown that vibration monitoring in two planes is essential to identify the causes of this failure. The symptoms of shaft misalignment are produced clearly in the plane that is produced, and not in the other. Symptoms identified are listed below.

- Different vibration response in both planes.

- Shaft orbits in an "elliptical" or "eight" shape, the approximate circular shape (polar diagram).

- Increment of $1 \mathrm{X}$ and $2 \mathrm{X}$ response, and simultaneity of both responses (cascade spectrum).

- Important $1 \mathrm{X}$ response in frequency equal to half of its resonance frequency.

In the case of rubbing shaft/seal, the modification of the dynamic stiffness also occurs in the misaligned plane, but just in another plane.

In the case of rubbing shaft/sealing seal, the modification of the dynamic stiffness also occurs in the misaligned plane, but hardly in another plane.

(2) All these data related to the vibration of the equipment, cannot be obtained exclusively with contact transducers such accelerometers placed superficially on supports and benches.

The common practice of installing an accelerometer in the system may reflect a situation of amplitude of high vibration, which would indicate an anomaly but not its cause. In addition, in the case of the tidal turbines the shaft coupled to the propellers rotates at approximately $30 \mathrm{rpm}$, and at these low revolutions these transducers have no utility and/or precision.

(3) It has been demonstrated how by monitoring and interpreting the response of the vibration of a rotor can detect anomalies as frequent as misalignment in a rotating system and its immediate consequences, such as rubbing the rotor/stator. This situation predicts serious failures in the machines.
(4) In the case of tidal turbines, which are in full development of research and application as important sources of sustainable energy, a technical-economic failure of its facilities can risk the future of this project, and therefore the great importance of having already, from the origin of its operation, with a system of prediction of serious failures as the proposed one, which avoids this failure

(5) To have good control of the machine, it is necessary that the implantation of the transducers be carried out in the period of manufacture of the machine, and therefore be taken into account by the designers, in order to incorporate the necessary elements of its installed during manufacturing.

Acknowledgements The authors sincerely thanks to Professor Dr. Alfonso Loureiro Montero, A Coruña University, Spain for his critical discussion and reading during manuscript preparation and Dr. Kim Last of University of the Highlands an Islands, Scotland, for his invaluable support in the research. To Eddie Boyd, Senior Engineer of the Depart. of Energy and Sustainability of Highlands Council of Scottish Government, for their invaluable support.

Authors' contributions The author' contributions are as follows: was in charge of the whole trial and wrote the manuscript.

Funding Supported by the Department of Naval and Industrial Engineering of the University of A Coruna, the Foundation of the University of A Coruña (Grant), the "University of the Highlands" and Islands of Scotland-Inverness College: Marine, Environmental Science and Engineering, the Department of Energy and Sustainability of Highlands Council of Scottish Government and European Union FP7 Project.

Data availability The datasets supporting the conclusions of this article are included within the article.

\section{Compliance with ethical standards}

Conflict of interest The authors declare no competing financial interests.

Consent for publication Not applicable.

Ethics approval and consent to participate Not applicable.

\section{References}

1. "ORJIP (Offshore Renewables Joint Industry Programme," 2015. [Online]. Available: www.orjip.org.uk. [Accessed September 2017]

2. OCEANERA-NET (2014) 15 national and regional funders and managers of research and innovation programmes, European Union's Seventh Programme for research technological development and demonstration under grant agreement No. 618099., Bruselas

3. Zheng J, Dai P, Zhang J (2015) Tidal stream energy in China, in 8th International Conference on Asian and Pacific Coasts (APAC 2015) 
4. EMEC: THE EUROPEAN MARINE ENERGY CENTRE Ltd. (2015) Orkney KW16 3AW. Scotland, United Kingdom

5. Li Y and Florig HK (2012) Modeling the Operation and Maintenance Costs of a Tidal Turbine., Carnegie Mellon University, Pittsburgh, USA

6. Elasha F, Teixeira M (2014) Condition Monitoring Philosophy for Tidal Turbines. International Journal of Performability Engineering 10(5):521-534

7. Togneri M, Elasha F, Allmark M (2015) Unsteady BEMT for fault diagnosis and prognosis in tidal stream turbines, in European Wave and Tidal Energy Conference, Nantes

8. Chudzik A, Warda B (2016) Effect of ring misalignment on the fatigue life of the radial cylindrical roller bearing., International Journal of Mechanical sciencies, vol. 111, no. March 2016, pp. 1-11

9. Jang J, Khonsari M (2016) On the Relationship between Journal Misalignment and Web Deflection in Crankshafts, Journal of Engineering for Gas Turbines and Power, vol. 138, no. December

10. Sampaio L, Nicoletti R (2016) Detection of cracks in shafts with the Approximated Entropy, Mechanical Systems and Signal Processing, pp. 286-302

11. Galloway LM, Bahaj A (2014) Quantifying wave and yaw effects on a scale tidal stream turbine, Renewable Energy, pp. 297-307

12. Kirke B, Lazaukas L (2008) Variable Pitch Darrieus Water Turbines. J Fluid Sci Technol 3(3):430-438

13. Eshleman R, Jackson C (1992) Data Adquisition Procedures, in Handbook of rotordynamics, New York, McGraw-Hill, pp. 4.94.22

14. Muszynska A (1999) Misaligment Model, Bently Rotor Dynamic Research Corporation., Minden, Nevada. USA

15. Muszynska A (1995) Vibrational Diagnostics of Rotating Machinery. International Journal of Rotating Machinery I(3-4): 237-266

16. Ehrich FF (1992) Chapter 4. Performance Verification, Diagnostics, parameter Identification, and condition Monitoring of Rotating Machinery, in Handbook of Rotor Dynamics, McGraw-Hill, pp. 4.1-4-54

17. Muszynska A (1982) Introduction to dynamic motion of mechanical syatems (pp. 1-39), BRDRC Report $n^{\circ} 2$. Bently Nevada Corporation, Minden Nevada, USA
18. Bently DE, Yu JJ and Godman P (2002) Full Annular Rub in Mechanical Seals, International Journal of Rotating Machinery, pp. $319-328$

19. Warda B and Chudzik A (2016) Effect of ring misalignment on the fatigue life of the radial cylindrical roller bearing, International Journal of Mechanichal Sciences, vol. 111, no. June, pp. 1-11

20. Li S-Y, Zhang W-G, Hou J-Z and Guo B-T (2017) Research on Dynamic Stiffness of Vibration Isolator, in Acta Armamentarii 38(11), Binggong Xuebao

21. Jang E, Muszynska A, Park Y, Kim C (1996) Identification of the Quadrature Resonances Using Modal Nonsynchronous Perturbation Testing and Dynamic Stiffness Approach for an Anisotropic Rotor System. International Journal of Rotating Machinery 2(3):188-201

Publisher's Note Springer Nature remains neutral with regard to jurisdictional claims in published maps and institutional affiliations.

Beatriz Fraga De Cal , born in 1987, she is currently a $\mathrm{PhD}$ student at the University of A Coruña-Polytechnic College of Engineering, Spain: Course and writing of doctoral thesis: "Analysis of the conditions of the state in tidal turbines by vibratory study". She obtained his Master's degree in Mechanical Engineering from "Antonio de Nebrija" University, Madrid-Spain, in 2012; University Master of research in naval and industrial technologies, in A Coruña, in 2013; and Master: MSc. Sustainable energy systems at Queen Mary University of London, UK at 2014. She is currently a Mechanical Engineer in energy and sustainability design in Highlands Scotland. United Kingdom. His main research interests include: energy efficiency, renewable energies and machine dynamics. 